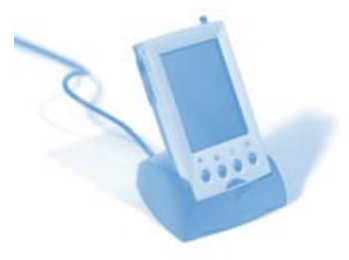

\author{
Lynn Moran \\ Department of Physics \\ University of Liverpool \\ Liverpool \\ L69 3BX
}

lynn.moran@liverpool.ac.uk

\section{In making changes the} aims were to improve student engagement with the material in order that the long period between delivery and examination be less of an issue, and to encourage the students to apply their knowledge to problems throughout the module.

\section{Problem-based learning in physics supported by electronic assessment (Mastering Physics)}

\begin{abstract}
Problem Based Learning (PBL) was introduced into a year 1 module in physics in the University of Liverpool in 2008/09. Mastering Physics (MP) electronic assessment from Pearson was also introduced to support this change. The main alteration was that for the purposes of continuous assessment the three tutorial-style homework assignments worth $10 \%$ of the module mark, were replaced with four group projects and 6 MP electronic assessments worth $30 \%$ of the module mark in 2008-09, and $50 \%$ in $2009-10$. The most notable improvement is from $\sim 45 \%$ of students submitting three assignments, claiming to have spent $\sim 30$ minutes per week on them, and achieving an average mark of $<50 \%$, to over $80 \%$ of students in 2008-09, and over 95\% in 2009-10 submitting work for all projects and electronic assessments, with feedback indicating an average of 5-6 hours per week of work outside class. The average and median marks also improved dramatically from $<50 \%$ in 2007-08 to $>70 \%$ in 2008-09 and $>75 \%$ in 2009-10.
\end{abstract}

\section{Background}

Thermal Physics is a short module which takes place during the first half of semester 2. Previously the 100 students attended 15-18 lectures and completed three typical homework assignments containing of the order of 5 tutorial-style single or 2-step problems worth $10 \%$ of the module mark. Despite very positive feedback on lectures, it was clear that students struggled to apply the theory to simple problems in the assignments. A further problem arose as the examination date is approximately eleven weeks after the final session of the module.

\section{Aims \\ In making changes the aims were to improve student engagement with the material in order that the long period between delivery and examination be less of an issue, and to encourage the students to apply their knowledge to problems throughout the module.}

\section{Logistical Changes:}

Continuous Assessment (CA)

The portion of marks for CA increased from $10 \%$ to $30 \%$ in $2008-09$ (50\% in 2009-10).

- $\quad$ CA changed from 3 tutorial-style homework assignments to 4 group projects and 6 MP electronic assignments.

- Mastering Physics electronic assessment introduced.

Delivery.

- Class divided into two groups for facilitation session once per week in 2008-09 (twice per week in 2009-10).

- Moved from tiered lecture theatre to flat room with moveable tables.

- Post-graduate facilitators present.

\section{The Module in PBL Format}

Introduction

The PBL summer workshop run by Derek Raine, Sarah Symons, and Cheryl Hurkett of piCETL at Leicester allowed me to benefit from advice from experienced practitioners. It was emphasised that the manner of introduction to PBL was very important. Therefore the first week of my limited time was devoted to an introductory project on a topic with which the students would already be familiar ${ }^{1}$ :

'You are interested in purchasing a new 'green' car.

Which one should you buy in order to minimise the overall cost?' 
Problem 20.48: Thermodynamic Processes for a Refrigerator

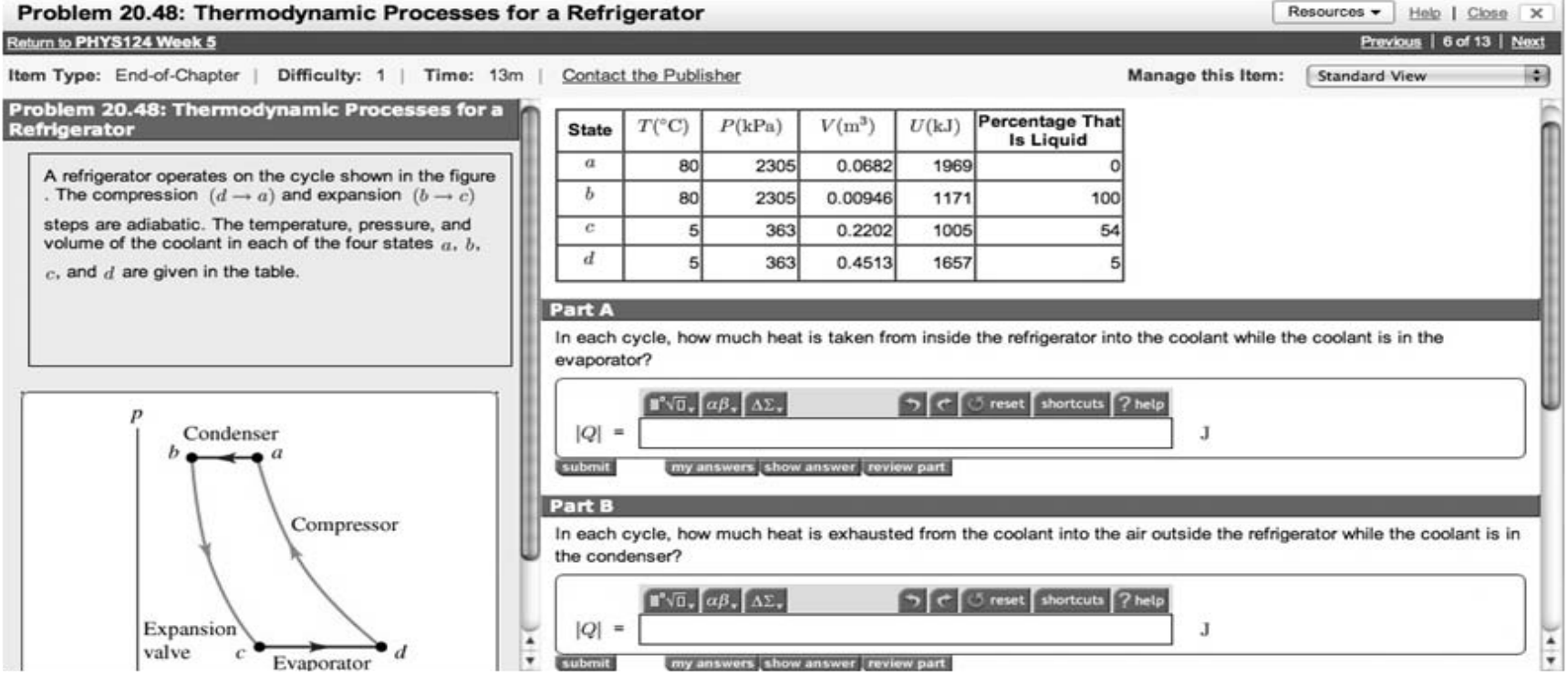

Figure 1: Screenshot of a Mastering Physics 'End-of-Chapter' question, www.masteringphysics.com.

The level of physics varied in the reports submitted, but this project allowed the students to settle into PBL, for group dynamics to develop, and the facilitators to establish a relationship with their groups. Feedback indicates that the students viewed the introductory project as beneficial to their learning within PBL.

\section{Running PBL}

The other 3 projects were developed from those developed by Paul van Kampen and Eilish McLoughlin at Dublin City University ${ }^{2}$. A group report was submitted for each project, and marked overnight to increase the impact of the feedback. The next morning each group was paired with another group whose report had alternative strengths. The groups presented their work to each other, observed by the facilitators. The groups were expected to question and discuss the findings of the other group and make notes. This was the stimulus for a class discussion of the learning outcomes of the just-completed project.

There was clear evidence in the examination (2008-09) that some students had not understood all of the material in their project (highlighted by a few students on the evaluation forms); also students' ability to transfer their knowledge to new scenarios varied. In 2009-10 tutorial-style questions were introduced after the discussion of learning outcomes, requiring students to apply their knowledge to a new, albeit simpler, problem requiring understanding of the whole project, not just their own section.

\section{Techniques Sessions}

One session per week was labeled a 'techniques session' in which resources determined that the whole class work in a tiered lecture-theatre with one member of staff. Students were asked to sit in their groups and some new material and an overview linking aspects of the different projects were presented in the form of an interactive lecture. All material was delivered in the form of problems, which the groups attempted to solve, before the outline of a solution was presented.

\section{Mastering Physics}

Mastering Physics (MP) is an online system containing physics questions at year 1 level. The product is sold by Pearson Education as part of a book purchase or in a stand-alone format. Students register for the course linked to their programme of study, and complete assignments set by lecturing staff.

The question library is divided into chapters according to the associated book. Assignments can be set for a defined period, with a controlled marking system (e.g. three attempts, credit for first attempt only), hints are available, and feedback to their attempts is immediate. Questions are divided into three types: 'tutorial questions' include text to remind/teach the students, 'end-of-chapter' questions involve 2- or 3-stages of working out, and 'multiple choice questions' do exactly what it says on the tin. Marks and time taken are recorded for each student and assignment allowing easy analysis.

\section{Analysis \& Results}

A major change from previous years was the amount of time the students spent on the module outside contact hours. The time spent on Mastering Physics is automatically logged and correlates both with their self-evaluation at the end of the module (average 5-6 hours per week outside of class), and the marks achieved in the final examination 11 weeks later.

Table 1: $2007-08$ (pre-PBL): 3 homework assignments worth 10\% of module mark.

\begin{tabular}{|l|l|l|l|}
\hline Tutorial Homework & 1 & 2 & 3 \\
\hline Average mark 2007-08 & 45 & 37 & 50 \\
\hline Median mark 2007-08 & 45 & 30 & 45 \\
\hline Students (\%) 2007-08 & 62 & 49 & 40 \\
\hline
\end{tabular}




\section{Continuous Assessment}

In $2007-0862 \%$ of the students attempted the first homework assignment achieving an average mark of $45 \%$ (Table 1 ). Homeworks 2 and 3 were attempted by $49 \%$ and $40 \%$ of students respectively with average marks of $37 \%$ and $50 \%$; these marks are representative of the trend over the previous five years. The reason for the increase in the final piece of work can be attributed to two main factors; first the material was based on use of the Ideal gas law, familiar to many of them from A-level (particularly those who did chemistry) and, second, the $40 \%$ who submitted work were those with better attendance and higher marks in general.

In the first year of PBL, over $90 \%$ of students submitted work for each project, and $\sim 80 \%$ completed the individual, weekly Mastering Physics electronic assignments (Tables $2 \& 3$ ). The average (73\% for projects, $74 \%$ for MP electronic assessments) and median marks (76\%, 80\%) are much higher than in previous years for this different type of assignment, although the level of the material is the same. The proportion of students submitting work and the marks, both average and median, increased further in 2009-10. Of 107 students only 3 students failed to submit work for every project. The average mark achieved was $76.3 \%$, the median $78 \%$. MP electronic assignments were completed by $~ 95 \%$ of students each week achieving an average mark of $78 \%$.

\section{Table 2: 2008-09/2009-10: 4 PBL projects worth 20\% of module mark.}

\begin{tabular}{|l|l|l|l|l|}
\hline Project & 1 & 2 & 3 & 4 \\
\hline Average mark 2008-09 & 69 & 73 & 73 & 76 \\
\hline Average mark 2009-10 & 75 & 70 & 80 & 79 \\
\hline Median mark 2008-09 & 75 & 76 & 75 & 78 \\
\hline Median mark 2009-10 & 77 & 70 & 85 & 82 \\
\hline Students (\%) 2008-09 & 100 & 94 & 91 & 89 \\
\hline Students (\%) 2009-10 & 100 & 100 & 97 & 97 \\
\hline
\end{tabular}

Table 3: 2008-09: 6 Mastering Physics electronic assessments worth $10 \%$ of module mark.

\begin{tabular}{|l|l|l|l|l|l|l|}
\hline MP Assignment & 1 & 2 & 3 & 4 & 5 & 6 \\
\hline Average mark 2008/09 & 65 & 78 & 77 & 80 & 71 & 71 \\
\hline Average mark 2009-10 & 79 & 74 & 78 & 76 & 73 & 88 \\
\hline Median mark 2008-09 & 66 & 83 & 84 & 88 & 80 & 80 \\
\hline Median mark 2009-10 & 89 & 80 & 85 & 81 & 77 & 96 \\
\hline Students (\%) 2008-09 & 91 & 87 & 82 & 68 & 74 & 77 \\
\hline Students (\%) 2009-10 & 95 & 94 & 95 & 94 & 95 & 96 \\
\hline
\end{tabular}

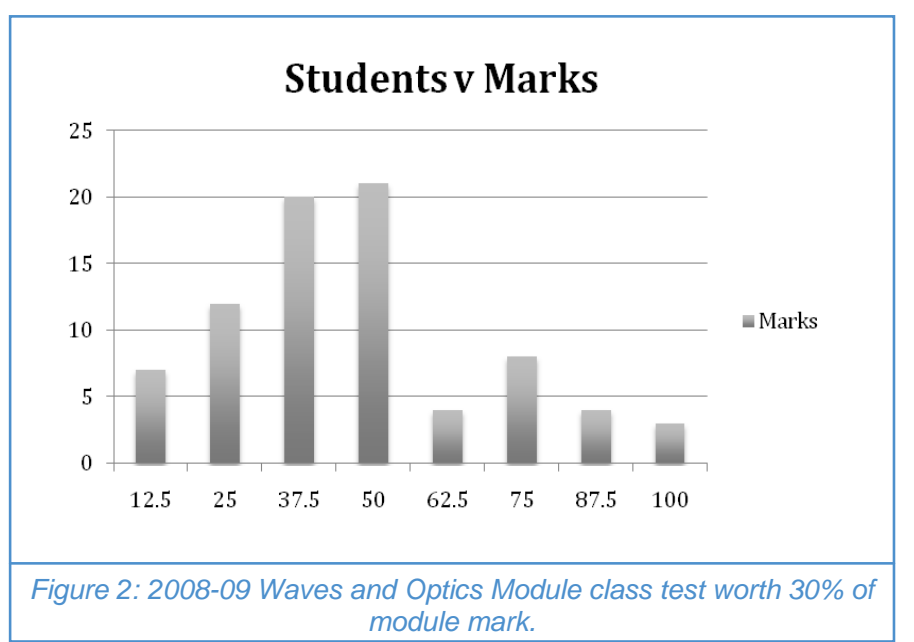

Comparison with other modules

In the same semester, two other short modules delivered to the same class, made significant changes to the delivery or assessment, in particular they also increased the portion of marks for continuous assessment from $10 \%$ to $30 \%$.

Attendance in both modules was significantly less, $53 \%$ in both, compared to the PBL module where attendance was $\sim 78 \%$.

One module offered 2-hour problem classes where the students were encouraged to work in their groups and support was given through staff and postgraduate demonstrators. In the penultimate week a class test worth $30 \%$ was set, using only problems from the problem classes; only $40 \%$ of the class passed (Figure 2).

The other module changed two of the three tutorial-style homework assignments to MP electronic assessments. The second homework consisted of two parts: one paper-based, one electronic. This assignment was completed by $80 \%$ of students achieving an average mark of $73 \%$. However, two weeks later the final assignment (electronic format only) was completed by only $58 \%$ of students achieving an average mark of $42 \%$, although the material is not considered to be more difficult and the decrease in effort and marks does not correspond to what was seen in previous years for that section of the module.

As the increase in the portion of marks for continuous assessment was consistent across all three modules, but did not result in a similar improvement in attendance, submission of work, and marks, it strongly indicates that the students were motivated by the PBL projects. This is supported by feedback received in the evaluation process.

\section{Examination}

In order to be able to both compare with previous years' marks and evaluate the influence of PBL, half the examination paper was left in the old format, while the other half was changed. The average mark was within the usual $3 \%$ fluctuation, and on average $44 \%$ of students' marks came from the newer style question. This question attempted to assess the students' ability to model problems after their exposure to $\mathrm{PBL}^{2}$. 


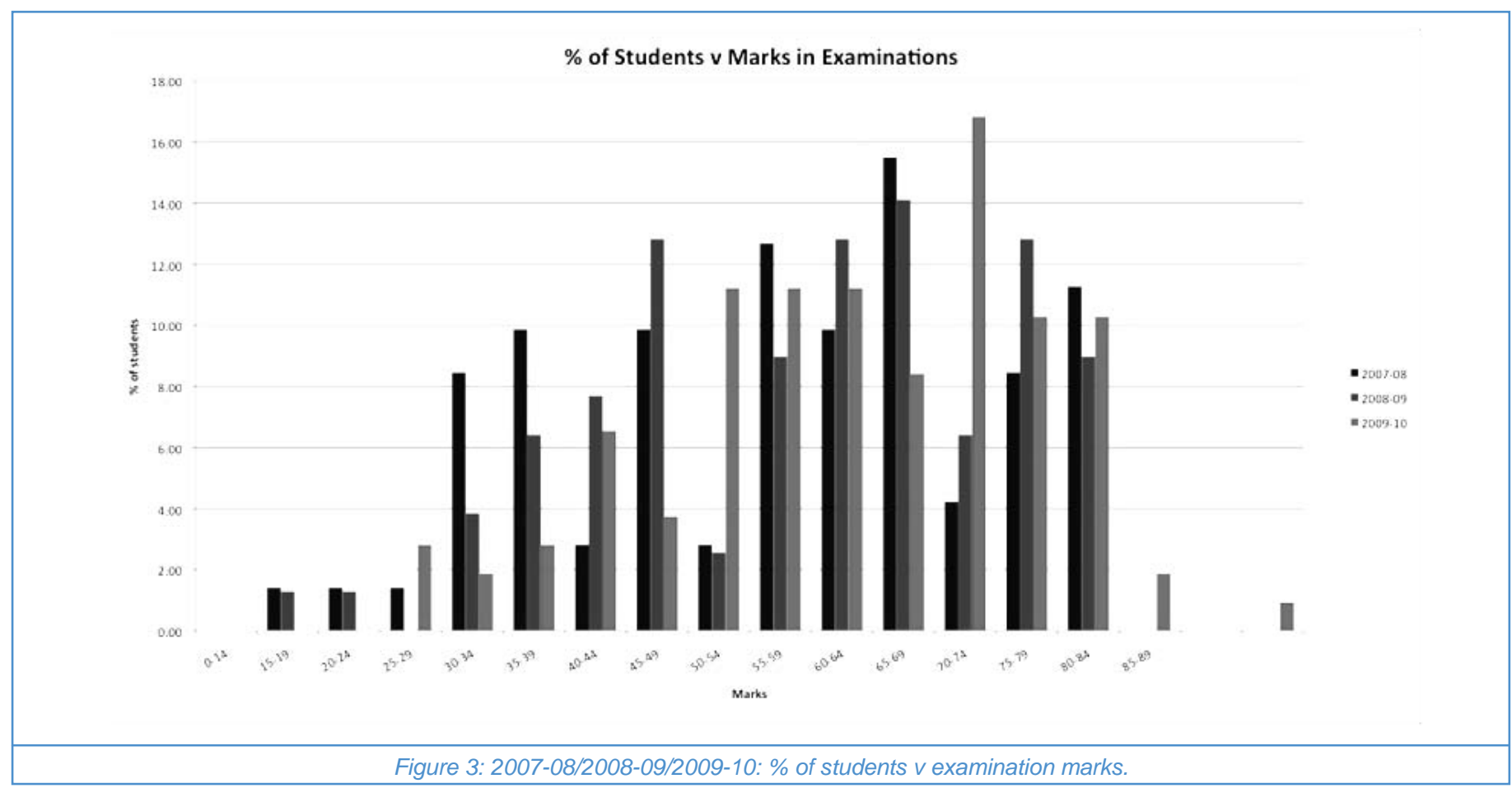

The main difference observed was that students wrote a great deal more than in previous years. Students attempted to justify their choice of equations in words even when not directly asked to, as in the question which remained in the same format as previous years. The examination was further developed in 2009-10 to include more 'unseen' questions, and organised in such a manner that it is no longer possible for the students to complete the paper if they chose to ignore a section of the module. Although the paper was considered to be more difficult by the staff, the average mark increased by $6 \%$ to $63 \%$. Of those who missed projects, 2 obtained $<30 \%$ in the examination and the other $44 \%$. Unsurprisingly, the four students with the poorest attendance also obtained $<40 \%$ in the examination. Figure 3 illustrates a comparison of the examination marks for the two years.

\section{Repeat Students}

Two students had completed the module in 2007-08 but failed to progress to year 2; their marks are shown in Table 4. Both students are (young) mature students who entered university through access programmes, and described their experience of the module as 'Very engaging and inspiring' and 'Applying methods allowed me to absorb information better.'

Both students were also repeating two other modules in the same semester and showed only a very small improvement in the continuous assessment and examination marks in both modules.

\section{Conclusions}

Overall the introduction of PBL and MP has been a success. There has been an improvement in both engagement and marks. As the portion of the marks for continuous assessment was increased to $50 \%$ of the module, meaning $~ 10 \%$ of students passed on the basis of $C A$, it was very positive to see full attendance and good understanding shown in the exam. Both the 2009-10 examination and the year 2 follow-on module examination from the previous cohort show excellent ability to work through a problem via an understanding of the underlying physics, not obvious in other modules of the same cohorts of students.

Further evidence of achieving our original aims is that feedback from both years confirmed, in agreement with student comments highlighted by Van Kampen et al. (2004) ${ }^{2}$, 'it was easier to revise as I remember what was covered in the module better from having to research the information and apply it.'

\section{References}

1. Raine D. and Symons S., (Eds.), (2005), PossiBiLities: A Practice Guide to Problem-based Learning in Physics and Astronomy, The Higher Education Academy Physical Sciences Centre, ISBN 1-903815-14-2. $<$ www.physsci.heacademy.ac.uk/Publications/ PracticeGuides.aspx>

2. VanKampen P., Banahan C., Kelly M., et al., (2004), Teaching a single physics module through Problem Based Learning in a lecture-based curriculum, Am. J. Phys., 72 (6).

Table 4: Continuous assessment (CA) and final examination marks for 2 repeat students.

\begin{tabular}{|l|l|l|l|l|l|}
\hline Assessment & CA 08 & Exam 08 & Repeat 08 & CA 09 & Exam 09 \\
\hline Student 1 & $0 \%$ & $4 \%$ & $36 \%$ & $77 \%$ & $52 \%$ \\
\hline Student 2 & $0.60 \%$ & $0 \%$ & $12 \%$ & $87 \%$ & $62 \%$ \\
\hline
\end{tabular}

